\title{
O PAPEL DO BRASIL NO SISTEMA INTERAMERICANO DE DIREITO HUMANOS
}

\author{
THE ROLE OF BRASIL IN THE INTER-AMERICAN SYSTEM OF HUMAN \\ RIGHTS
}

\author{
${ }^{1}$ Leonardo Cordeiro Sousa \\ ${ }^{2}$ Saul Duarte Tibaldi
}

\section{RESUMO}

Este trabalho, através do método de pesquisa bibliográfico, tem como objetivo analisar o papel do Brasil no Sistema Interamericano de Direitos Humanos ao explicitar sua postura em diferentes momentos que contribuíram ora para o fortalecimento, ora para o enfraquecimento do Sistema de Proteção. Para tanto, será estudada a atuação do Estado Brasileiro no período anterior à redemocratização (1948-1985); a postura do Brasil no período posterior à redemocratização (1985 até março de 2011); a atuação do Brasil a partir de abril de 2011; e a influência da ação penal 470 na postura diplomática do país.

Palavras-chaves: direitos humanos; Sistema Interamericano de Direitos Humanos; papel do Brasil.

\begin{abstract}
This paper, through the bibliographic method, aims to analyse the role of Brazil in the interamerican system of human rights by making explicit its position at different moments that contributed sometimes to the strengthening, sometimes to the weakening of the protection system. To do so, we will study the performance of the Brazilian State, in the period before redemocratization (1948-1985); and the position of Brazil in the período after redemocratization (1985 to March 2011); the position of Brazil since April, 2011; and the influence of the criminal action 470 in the diplomatic position of the country.
\end{abstract}

Keywords: human rights; inter-american system of human rights; role of Brazil.

\footnotetext{
1 Mestrando em Direito Agroambiental pela Universidade Federal de Mato Grosso - UFMT, Mato Grosso (Brasil). Pesquisador do Grupo de Pesquisa nominado Direito do Trabalho Contemporâneo pela Universidade Federal de Mato Grosso - UFMT, Mato Grosso (Brasil). E-mail: leocordeiro2@gmail.com

2 Doutor em Direito do Trabalho pela Pontífice Universidade Católica - PUC, São Paulo (Brasil).

Professor Adjunto e Diretor da Faculdade de Direito pela Universidade Federal de Mato Grosso - UFMT, Mato Grosso (Brasil).
} 


\section{INTRODUÇÃO}

Este estudo, através do método de pesquisa bibliográfico, se destina a analisar o papel do Brasil no Sistema Interamericano de Direitos Humanos (SIDH). Ao longo da história do SIDH, a República Federativa do Brasil, na maior parte do tempo, tem sido uma importante aliada.

O Brasil, no período compreendido entre 1948 até 1985, foi um grande percussor da construção do Sistema Interamericano, com atuação incisiva inclusive para que uma Convenção Americana de Direitos Humanos fosse elaborada e uma Corte Interamericana de Direitos Humanos criada. Não obstante, sobretudo em virtude do regime militar imposto, não houve avanços com relação à ratificação de tratados interamericanos de proteção de direitos humanos.

Com a redemocratização, a partir de 1985 iniciou-se uma fase de ratificação dos tratados interamericanos de direitos humanos e implementação do Governo de esforços no âmbito interno do país para a promoção e proteção dos direitos humanos. Tais fatos se deram sobretudo após a promulgação da Constituição Federal de 1988.

Contudo, a partir de $1^{\circ}$ de abril de 2011, data em que a Comissão Interamericana de Direitos Humanos determinou ao Brasil uma série de medidas relativas à suspensão do licenciamento ambiental e obras da usina hidroelétrica de Belo Monte, no âmbito da Medida Cautelar 382/2010 (Belo Monte), o Brasil acabou enfraquecendo o Sistema de Proteção.

Por fim, dedicaremos uma análise especial atenção à influência da Ação Penal 470 (mensalão) com relação à postura do Brasil para com o Sistema Interamericano de Direitos Humanos.

\section{A ATUAÇÃO DO ESTADO BRASILEIRO COM RELAÇÃO AO SISTEMA INTERAMERICANO DE DIREITOS HUMANOS (SIDH) ATÉ MARÇO DE 2011}

A República Federativa do Brasil, com efeito, tem uma tradição histórica na diplomacia internacional referente a direitos humanos. Este tópico se destina exatamente abordar esta tradição com relação ao Sistema Interamericano de Direitos Humanos (SIDH) até março de 2011.

Nesse período, o Estado brasileiro mostrou uma evolução salutar em matéria de promoção e proteção dos direitos humanos e também com relação ao fortalecimento do Sistema 
Interamericano. A política externa brasileira, mesmo durante o regime militar, sempre foi ativa com relação à formulação de tratados interamericanos ligados à proteção dos direitos humanos, ainda que a ratificação deles não tenha se dado até 1985. Ademais, pouco era feito com relação à proteção interna dos direitos humanos no Brasil.

Foi no período da redemocratização, sobretudo a partir da Constituição Federal de 1988, que o país aliou o seu pioneirismo diplomático com a ratificação dos tratados interamericanos de direitos humanos. Somado a isto, destaca-se também o desenvolvimento de uma política interna de direitos humanos que levou o Brasil a uma escalada na proteção e promoção dos direitos humanos, ainda que muito tenha que ser feito para um nível de proteção satisfatório.

\section{O PERÍODO ANTERIOR À REDEMOCRATIZAÇÃO (1948-1985)}

O Brasil, no período anterior à redemocratização (1948-1985), teve uma postura bastante ativa com relação à promoção do fortalecimento do Sistema Interamericano de Direitos Humanos. A atitude do Estado, entretanto, não deixou de ser contraditória em certos aspectos, isto se confrontarmos a postura diplomática brasileira intensa na elaboração dos tratados regionais de direitos humanos com a realidade política do país, sobretudo a partir da instauração do regime militar em 1964.

Não obstante essa incongruência, a qual nos reportaremos mais adiante, o Brasil teve participação importante na IX Conferência Internacional Americana, realizada em Bogotá, quando foram adotadas a Carta das Organizações dos Estados Americanos e a Declaração Americana de Direitos e Deveres do Homem. O protagonismo brasileiro em matéria de direitos humanos bem se nota pela proposição feita por intermédio da Delegação do Brasil de uma Corte Interamericana de Direitos Humanos. A tese brasileira foi adotada como a Resolução XXI da Conferência de Bogotá (CASTRO, 2013, p. 81). Tal resolução "ressaltava a necessidade da criação de um órgão judicial internacional para tornar adequada e eficaz a proteção jurídica dos direitos humanos internacionalmente reconhecidos" (TRINDADE, 2000, p. 39).

Dessa forma, já no ano de 1948 o Brasil reconhecia a necessidade de criar um Tribunal Interamericano para tornar mais eficaz a proteção dos direitos humanos na América, em virtude das recorrentes violações perpetradas pelos Estados.

$\mathrm{Na}$ X Conferência Interamericana, ocorrida em Caracas, capital da Venezuela, em 1954, o Brasil propugnou pelo reconhecimento da personalidade jurídica do indivíduo no âmbito 
internacional (VENTURA; CETRA, 2013). Na V Reunião de Ministros das Relações Exteriores, realizada em Santiago, capital do Chile, em 1959, quando foi criada a Comissão Interamericana de Direitos Humanos, o Estado Brasileiro sustentou que os Estados Americanos deveriam se empenhar a tornar obrigatórias as normas do Sistema Interamericano, por meio de uma convenção de proteção de direitos humanos (CASTRO, 2013, 82).

Como consequência, na II Conferência Interamericana Extraordinária, ocorrida no Rio de Janeiro, em 1965, o Brasil apresentou um projeto que foi utilizado como base à Resolução XXIV da Conferência relativa ao Projeto de Convenção Americana sobre Direitos Humanos. O Brasil, na III Conferência Interamericana Extraordinária, ocorrida em Buenos Aires, em 1967, novamente realçou urgência da Convenção Americana de Direitos Humanos (CASTRO, 2013, 82).

Entretanto desde $1^{\circ}$ de abril de 1964 o Estado Brasileiro estava submetido ao regime militar. O ano de 1968 foi particularmente marcado pelo recrudescimento da ditadura militar, haja vista que em 13 de dezembro de 1968 foi editado o AI-5, que agravou a repressão política e a violência do regime. Mesmo assim, o Brasil participou de forma ativa da Conferência Especializada Interamericana sobre Direitos Humanos, realizada em San José da Costa Rica, em novembro de 1969, que resultou na assinatura da Convenção Americana sobre Direitos Humanos. 3

A despeito das críticas em virtude do regime ditatorial instaurado, a postura do Brasil na Conferência, através de seus representantes, foi eminentemente técnica. Tanto é que o país apresentou considerações ao projeto da Convenção Americana sobre Direitos Humanos, mas o que chama atenção é que o Estado Brasileiro, "na Exposição de Motivos, observava que seria inoportuna a criação de uma Corte Interamericana de Direitos Humanos” (CASTRO, 2013, p. 84). Não obstante isto a Convenção só foi aprovada no Brasil pelo Decreto Legislativo 27, de 25 de setembro de 1992, e promulgada pelo Decreto 678, de 6 de novembro de 1992.

\subsection{O período pós à redemocratização (1985 até março de 2011)}

Foi no período pós redemocratização, sem dúvida alguma, que o Brasil mais contribuiu, nacional e internacionalmente, para a promoção dos direitos humanos. Isto, por que somente

\footnotetext{
3 Cf. Convenção Americana sobre Direitos Humanos. Disponível em: http://www.cidh.oas.org/basicos/portugues/c.convencao_americana.htm. Acesso em: 19 de agosto de 2015.
} 
após 15 de março de 1985 - fim da ditadura militar - o país, além do protagonismo diplomático em elaborar tratados de direitos humanos, passou também a ratificá-los, tornando-os obrigatórios em solo brasileiro.

Foi mais precisamente a partir da promulgação da Constituição Federal de 1988, a qual alçou o princípio da prevalência dos direitos humanos como norteador do país em suas relações internacionais, que o Brasil vem elaborando medidas com o intuito de adotar os mais diversos tratados internacionais de direitos humanos (MAZZUOLI, 2002, p 327-333).

Flávia Piovesan bem destaca os principais tratados que foram ratificados após a promulgação da Constituição de 1988, a saber: 1) a Convenção Interamericana para Prevenir e Punir a Tortura, em 20 de julho de 1989; 2) a Convenção contra a Tortura e outros Tratamentos Cruéis, Desumanos ou Degradantes, em 28 de setembro de 1989; 3) a Convenção sobre os Direitos da Criança, em 24 de setembro de 1990; 4) o Pacto Internacional dos Direitos Civis e Políticos, em 24 de janeiro de 1992; 5) o Pacto Internacional dos Direitos Econômicos, Sociais e Culturais, em 24 de janeiro de 1992; 6) a Convenção Americana de Direitos Humanos, em 25 de setembro de 1992; 7) a Convenção Interamericana para Prevenir, Punir e Erradicar a Violência contra a Mulher, em 27 de novembro de 1995; 8) o Protocolo à Convenção Americana referente à Abolição da Pena de Morte, em 13 de agosto de 1996; 9) o Protocolo à Convenção Americana em matéria de Direitos Econômicos, Sociais e Culturais (Protocolo de San Salvador), em 21 de agosto de 1996; 10) o Estatuto de Roma, em 20 de junho de 2002; 11) o Protocolo Facultativo à Convenção sobre a Eliminação de todas as formas de Discriminação contra a Mulher, em 28 de junho de 2002; e 12) os dois Protocolos Facultativos à Convenção sobre os Direitos da Criança, em 24 de janeiro de 2004 (PIOVESAN, 2006, p. 11-12). A jurisdição da Corte Interamericana de Direitos Humanos também só foi reconhecida em dezembro de 1998.

A par disso, o período pós Constituição Federal de 1988 apresentou a "mais vasta produção normativa de direitos humanos de toda a história legislativa brasileira" (PIOVESAN, 2006, p. 11-12).

E como Luiz Flávio Gomes e Valério de Oliveira Mazzuoli bem destacam:

No Brasil, a política nacional de Direitos Humanos começou a ser desenvolvida, efetivamente, a partir do retorno, em 1985, do governo civil, quando houve o desligamento autoritário instituído nos idos dos anos 70, onde reinava a violência arbitrária e o desrespeito às garantias individuais. Apesar de passado mais de meio século da proclamação da Declaração Universal dos Direitos Humanos, pela primeira 
vez o Estado brasileiro erigiu os Direitos Humanos como objeto de sua política nacional.4

Importa ainda destacar que 97\% dos casos contra o Brasil na Comissão Interamericana de Direitos Humanos foram propostos após 1992, ano em que o Brasil ratificou a Convenção Americana sobre Direitos Humanos. O interessante é que muitos deles se referem a fatos ocorridos antes deste ano, o que está a demonstrar a influência positiva que a ratificação da Convenção, aliada à nova postura do Estado brasileiro com relação à promoção dos direitos humanos no âmbito interno do país (PIOVESAN, 2009, p. 337-338). A respeito disso, Flávia Piovesan traz números interessantes:

(...) se no período de 1970 a 1992, ou seja, em 22 anos, 11 ações foram impetradas contra o Brasil, a partir da ratificação da Convenção Americana em 1992, e considerando o período de 1992 a 2004, em 12 anos portanto, um total de sessenta e sete ações foi impetrado (PIOVESAN, 2009, p. 338).

É certo que o Estado brasileiro, não tem cumprido satisfatoriamente as recomendações da Comissão Interamericana. Ocorre que o país, mais recentemente, com a submissão de casos à Corte pela Comissão, tem mostrado ao menos um diálogo maior com a Comissão Interamericana no que diz respeito ao cumprimento das recomendações, ao passo que alguns países, a exemplo dos Estados Unidos, permanecem relutantes em aceitar as recomendações da Comissão. O comportamento do Estado brasileiro com relação ao Sistema Interamericano de Direitos humanos, contudo, veio a sofrer significativa alteração com a edição da Medida Cautelar 382/10, como vamos abordar logo mais.

\section{4. $\quad$ A POSTURA DO BRASIL A PARTIR DE ABRIL DE 2011}

Como visto alhures, o Estado brasileiro exerceu uma importante função com relação ao fortalecimento do Sistema Interamericano de Direitos Humanos. Tal situação, contudo, sofreu uma significativa alteração a partir de $1^{\circ}$ de abril de 2011 , data em que a Comissão Interamericana de Direitos Humanos determinou ao Brasil uma série de medidas relativas à suspensão do licenciamento ambiental e obras da usina hidroelétrica de Belo Monte, no âmbito da Medida Cautelar 382/2010 (Belo Monte).

\footnotetext{
${ }^{4}$ Disponível em: http://www.egov.ufsc.br/portal/sites/default/files/anexos/15290-15291-1-PB.pdf. Acesso em: 21 de agosto de 2015.
} 
O tópico também abordará a influência da Ação Penal 470 (mensalão) na postura do Brasil com relação ao Sistema Interamericano, ao fazer uma breve análise da possibilidade de os réus que acionarem o Sistema de Proteção obterem judicialmente (Corte Interamericana) o direito a um novo julgamento, em virtude do princípio do duplo grau de jurisdição, inserto no $\operatorname{artigo~} 8^{\circ}, 2$, h, da Convenção Americana sobre Direitos Humanos

\title{
4.1. O comportamento do Estado brasileiro com a edição da Medida Cautelar 382/2010 (Belo Monte)
}

O proceder da República Federativa do Brasil com relação ao Sistema Interamericano de Direitos Humanos (SIDH) mudou substancialmente com outorga pela Comissão Interamericana de medidas cautelares no âmbito da Medida Cautelar 382, em $1^{\circ}$ de abril de 2011, a saber:

\begin{abstract}
A CIDH solicitou ao Governo Brasileiro que suspenda imediatamente o processo de licenciamento do projeto da UHE de Belo Monte e impeça a realização de qualquer obra material de execução até que sejam observadas as seguintes condições mínimas: (1) realizar processos de consulta, em cumprimento das obrigações internacionais do Brasil, no sentido de que a consulta seja prévia, livre, informativa, de boa fé, culturalmente adequada, e com o objetivo de chegar a um acordo, em relação a cada uma das comunidades indígenas afetadas, beneficiárias das presentes medidas cautelares; (2) garantir, previamente a realização dos citados processos de consulta, para que a consulta seja informativa, que as comunidades indígenas beneficiárias tenham acesso a um Estudo de Impacto Social e Ambiental do projeto, em um formato acessível, incluindo a tradução aos idiomas indígenas respectivos; (3) adotar medidas para proteger a vida e a integridade pessoal dos membros dos povos indígenas em isolamento voluntário da bacia do Xingú, e para prevenir a disseminação de doenças e epidemias entre as comunidades indígenas beneficiárias das medidas cautelares como consequência da construção da hidroelétrica Belo Monte, tanto daquelas doenças derivadas do aumento populacional massivo na zona, como da exacerbação dos vetores de transmissão aquática de doenças como a malária (CIDH, 2011).
\end{abstract}

As medidas cautelares foram prescritas em favor das comunidades indígenas da Bacia do Rio Xingu, situada no Estado do Pará, quais sejam: Arara da Volta Grande do Xingu; Juruna de Paquiçamba; Juruna do "Kilómetro 17”; Xikrin de Trincheira Bacajá; Asurini de Koatinemo; Kararaô e Kayapó da terra indígena Kararaô; Parakanã de Apyterewa; Araweté do Igarapé Ipixuna; Arara da terra indígena Arara; Arara de Cachoeira Seca; e também as comunidades indígenas em isolamento voluntário (CIDH, 2011).

Tais comunidades não haviam sido consultadas no processo de licenciamento ambiental e construção da Usina Hidroelétrica de Belo Monte, contrariando expressa disposição constitucional. Do caso resultou a Ação Civil Pública 2006.39.03.00711/8, julgada pelo 
Supremo Tribunal Federal (STF), o qual decidiu que os povos afetados poderiam ser ouvidos ao longo do processo de licenciamento. As obras foram retomadas, então, em janeiro de 2007 (TEIXEIRA, 2011, p. 220).

De acordo com indígenas e membros do Ministério Público Federal, que presenciaram o fato aqui narrado, os representantes da FUNAI visitaram não mais que duas aldeias e foram incisivos em afirmar que o encontro não era uma consulta, mas, sim, uma apresentação de um relatório com o fim de preparar as comunidades afetadas para uma consulta futura (TEIXEIRA, 2011, p. 220-221).

O Estudo de Impacto ambiental e o Relatório de Impacto Ambiental (EIA-RIMA), com mais de 20 mil páginas de informação técnica, só foi entregue aos representantes das comunidades afetadas dois dias antes das audiências públicas. À maior parte dos membros indígenas não foi oferecido transporte e hospedagem para participar das audiências. Quando da realização das audiências públicas, não foram disponibilizados intérpretes de português para as linhas de origem dos indígenas (TEIXEIRA, 2011, p. 221).

A construção da usina importaria em uma série de impactos ambientais e danos à saúde dos indígenas (TEIXEIRA, 2011, p. 222-224). Segundo Gustavo de Faria Moreira Teixeira:

\begin{abstract}
Os solicitantes das medidas cautelares enumeraram como prejuízos à população local decorrentes dos impactos negativos de Belo Monte, a violação do direito à vida, integridade e saúde; insegurança alimentar e hidrológicas; perda de propriedade das comunidades tradicionais e migração desordenada em decorrência das obras (2011, p. 224).
\end{abstract}

Em resposta às medidas cautelares, o Governo brasileiro, por meio de nota do Ministério das Relações Exteriores, afirmou que recebeu com perplexidade as determinações da Comissão e as considerou precipitadas e injustificáveis (MINISTÉRIO DAS RELAÇÕES EXTERIORES, 2011, nota 142). Em 26 de abril o governo enviou resposta sobre o caso, mas não divulgou o teor (TEIXEIRA, 2011, p. 225).

O Governo brasileiro retirou a candidatura de Paulo Vannuchi a uma vaga na Comissão de Direitos Humanos da Organização dos Estados Americanos (OEA) em 2012, convocou o embaixador Ruy Casaes na Organização e suspendeu o repasse de US\$ 800 (oitocentos mil dólares) em forma de colaboração voluntária à OEA para o ano de 2011.5

\footnotetext{
5 Declarações do diretor interino do Departamento de Direitos Humanos e Temas Sociais do Ministério das Relações Exteriores, Sílvio José Albuquerque e Silva, à Agência Brasil em 04.05.2011. Disponível em: http://memoria.ebc.com.br/agenciabrasil/noticia/2011-05-04/representante-do-itamaraty-diz-que-brasil-naodeslegitima-oea-por-medida-cautelar-sobre-belo-monte. Acesso em: 21 de agosto de 2015.
} 
Não só o governo, mas outras autoridades brasileiras também promoveram considerações truculentas contra a Comissão Interamericana de Direitos Humanos (VENTURA; CETRA, 2013). O Poder Legislativo não tardou a demonstrar apoio ao governo, porquanto, em 9 de junho de 2011, por iniciativa da Comissão de Relações Exteriores e de Defesa Nacional, “o plenário do Senado Federal aprovou um voto de solidariedade ao governo brasileiro e um voto de censura à CmIDH”' (VENTURA; CETRA, 2013).

Não bastasse os ataques advindos do Brasil, o próprio Secretário Geral da OEA à época, José Miguel Insulza, declarou à imprensa que esperava sinceramente que a Comissão revisasse a decisão e que o Brasil não fez nada de condenável ao não acatar a decisão.6

A Comissão Interamericana, como resultado, mudou o teor das medidas cautelares, não mais suspendendo o licenciamento e construção da usina, mas solicitando que o Estado brasileiro adotasse medidas para proteger a vida, a saúde, a integridade pessoal e a integridade cultural dos grupos indígenas afetados (CIDH, 2011).

Contrariando toda a história brasileira com relação ao Sistema Interamericano de Direitos Humanos, este lamentável episódio, como é evidente, desgastou a imagem da Comissão Interamericana e enfraqueceu o Sistema.

\subsection{A Ação Penal 470 (mensalão) e sua influência na postura do Brasil}

Não obstante o episódio referente à Medida Cautelar 382/10, o Governo brasileiro não tardou em renovar bons ânimos com relação à Comissão Interamericana de Direitos Humanos e, por conseguinte, com o Sistema Interamericano de Direitos Humanos, sobretudo ante à possibilidade de os réus, condenados no processo da Ação Penal 470-M (mensalão) no Supremo Tribunal Federal (STF), recorrendo ao Sistema Regional, obterem direito a um novo julgamento.

Queremos aqui não nos aprofundar na análise política do julgamento do mensalão, porquanto não é tema afeto à formação do jurista, mas, sim, do cientista político. A intenção é demonstrar, com arrimo em notável doutrina (MAZZUOLI, 2014, p. 833-847), que existe a possibilidade, por meio do Sistema Interamericano de Direitos Humanos, de os condenados na Ação Penal 470 receberem um novo julgamento. Evidentemente que se muitos dos réus forem

6 Comissão da OEA deve "revisar decisão" sobre Belo Monte, diz secretário-geral. Disponível em: http://www.bbc.com/portuguese/noticias/2011/05/110502_insulza_jc.shtml. Acesso em: 20 de agosto de 2015. 
aliados do Governo brasileiro, pode haver uma propensão para que o Brasil volte a fortalecer o Sistema Interamericano de Proteção dos Direitos Humanos.

Os réus do processo do mensalão que foram condenados o foram em única instância, tendo em vista que o STF é o órgão de cúpula do Poder Judiciário. Em virtude das regras de conexão instituídas pelo Código de Processo Penal brasileiro (art. 76, III e 78, III), os 38 réus da Ação Penal 470 foram julgados, em única instância, pelo Supremo, mas apenas três deles exerciam o mandato e estavam amparados pelo foro privilegiado perante a Corte Suprema.

Ocorre que o artigo $8^{\circ}, 2$, h, da Convenção Americana sobre Direitos Humanos, já ratificada pelo Brasil, dispõe o seguinte: toda pessoa acusada de delito tem o direito de recorrer da sentença para juiz ou tribunal superior. Com efeito, a Convenção não abre exceção para os julgamentos a serem feitos originariamente pelas Supremas Cortes dos países que a ratificaram, possibilidade existente no Sistema Europeu de Direitos Humanos (GOMES; MAZZUOLI, 2010, p. 135).

Como os réus do processo do mensalão foram julgados em única e última instância, há a possibilidade, caso eles recorram ao Sistema Interamericano, de ganharem o direito a um novo julgamento. O precedente da Corte Interamericana referente ao caso "Barreto Leiva vs. Venezuela" abordou situação semelhante, o qual Valério de Oliveira Mazzuoli trata com precisão:

\begin{abstract}
Naquele caso específico, cuidava-se de ação penal em que o Sr. Oscar Enrique Barreto Leiva (ex-diretor geral setorial de Administração e Serviços do Ministério da Secretaria da Presidência da Venezuela) respondia juntamente com o ex-presidente Carlos Andrés Péres e outras autoridades detentoras do foro privilegiado perante a Suprema Corte venezuelana. Barreto Leiva, contudo, não detinha a prerrogativa do foro como os demais réus. Porém, mesmo assim, em razão da regra da conexão, foi julgado pela instância máxima do Judiciário venezuelano, tendo sido condenado a um ano e dois meses de prisão por crimes contra o patrimônio público praticados durante a sua gestão, em 1989. Após condenado, Barreto Leiva recorreu à Comissão Interamericana de Direitos Humanos, que, em 2008, admitiu a queixa e fez recomendações à Venezuela. Ausente qualquer resposta do Estado, a Comissão submeteu, então, a causa à jurisdição da Corte Interamericana, que entendeu, ao final, que a Venezuela violara o direito (consagrado na Convenção Americana) relativo ao duplo grau de jurisdição ao não oportunizar ao Sr. Barreto Leiva o direito de apelar para um tribunal superior, eis que a condenação sofrida por este último proveio de um tribunal que conheceu do caso em única instância. Em outras palavras, entendeu a Corte que o sentenciado não dispôs, em consequência da conexão, da possibilidade de impugnar a sentença condenatória, o que estaria a violar a garantia do duplo grau prevista (sem ressalvas) na Convenção (MAZZUOLI, 2014, p. 837).
\end{abstract}

Assim, pode o Brasil ser condenado tanto pela Comissão Interamericana de Direitos Humanos como pela Corte Interamericana de Direitos Humanos. E não se diga que a interposição de embargos declaratórios (alguns com efeitos infringentes), como aconteceu no 
caso do mensalão, tem o condão, com absoluta certeza, de suprimir a garantia do duplo grau, porquanto a Corte pode interpretar com literalidade a referência no artigo $8^{\circ}, 2$, h, da Convenção Americana, do direito de recorrer a um “juiz ou tribunal superior” (MAZZUOLI, 2014, p. 846).

O interessante é observar que, após o imbróglio da construção da usina de Belo Monte, o Governo brasileiro comunicou em nota o lançamento da candidatura de Paulo Vannuchi à Comissão Interamericana de Direitos Humanos (MINISTÉRIO DAS RELAÇÕES EXTERIORES, 2013). Com a eleição de Vannuchi, o Governo lançou outra nota destacando que a eleição do candidato à CIDH fortalece o compromisso do Brasil com o fortalecimento do Sistema Interamericano de Direitos Humanos (MINISTÉRIO DAS RELAÇÕES EXTERIORES, 2013, nota 196). A dúvida que fica é a seguinte: se, aos olhos do Governo brasileiro, a eleição do candidato brasileiro aumenta o empenho do Estado com o fortalecimento do Sistema Interamericano, a retirada de sua candidatura, como ocorreu anteriormente, não serviria para demonstrar o empenho do Brasil com o enfraquecimento do Sistema?

\section{CONCLUSÃO}

Quanto ao papel do Brasil no Sistema Interamericano de Direitos Humanos, na maior parte do tempo o Estado agiu de modo a fortalecer o Sistema, mormente a partir da promulgação da Constituição Federal de 1988, quando inúmeros tratados de direitos humanos foram ratificados, leis infraconstitucionais publicadas e políticas públicas de proteção e promoção de direitos humanos implementadas, ainda que não se considere que o Estado brasileiro ostente um nível adequado de proteção.

As determinações da Comissão Interamericana no âmbito da Medida Cautelar 382/2010 (Belo Monte) provocaram uma reação truculenta do Governo brasileiro, que serviu para desgastar a imagem da própria Comissão e enfraquecer o Sistema Interamericano de Proteção, ao passo que o questionamento do julgamento da Ação Penal 470 em única instância pelo STF abre a possibilidade para mais uma mudança do Governo brasileiro no sentido de fortalecimento do Sistema.

Esse infeliz quadro de idas e vindas não pode mais subsistir, há que se respeitar o princípio constitucional da prevalência dos direitos humanos e os direitos fundamentais insculpidos na Constituição Federal de 1988. Para tanto, é preciso que o Brasil não só fortaleça o Sistema Interamericano dando apoio diplomático, ratificando as convenções e publicando leis em 
matéria de direitos humanos, mas, sim, que cumpra com maior rigor as recomendações da Comissão Interamericana de Direitos Humanos.

\section{REFERÊNCIAS BIBLIOGRÁFICAS}

CASTRO, Giovane Michelon de. Direitos humanos e a política externa brasileira: um diálogo com o sistema interamericano. Dissertação (Mestrado em Relações Internacionais) Instituto de Filosofia e Ciências Humanas da Universidade Federal do Rio Grande do Sul, 2013.

Comissão da OEA deve "revisar decisão" sobre Belo Monte, diz secretário-geral. Disponível em: http://www.bbc.com/portuguese/noticias/2011/05/110502_insulza_jc.shtml. Acesso em: 20 de agosto de 2015.

Convenção Americana sobre Direitos Humanos. Disponível em: http://www.cidh.oas.org/basicos/portugues/c.convencao_americana.htm. Acesso em: 19 de agosto de 2015.

Declarações do diretor interino do Departamento de Direitos Humanos e Temas Sociais do Ministério das Relações Exteriores, Sílvio José Albuquerque e Silva, à Agência Brasil em 04.05.2011. Disponível em: http://memoria.ebc.com.br/agenciabrasil/noticia/2011-0504/representante-do-itamaraty-diz-que-brasil-nao-deslegitima-oea-por-medida-cautelar-sobrebelo-monte. Acesso em: 21 de agosto de 2015.

GOMES, Luiz Flávio; MAZZUOLI; Valério de Oliveira. O Brasil e o sistema interamericano de proteção dos direitos humanos. Disponível em: http://www.egov.ufsc.br/portal/sites/default/files/anexos/15290-15291-1-PB.pdf. Acesso em: 21 de agosto de 2015.

GOMES, Luiz Flávio; MAZZUOLI, Valério de Oliveira. Comentários à Convenção Americana sobre Direitos Humanos: Pacto de San José da Costa Rica. 3. ed. ver., atual. e ampl. São Paulo: Revista dos Tribunais, 2010.

MAZZUOLI, Valério de Oliveira. Direitos humanos, Constituição e os tratados internacionais: estudo analítico da situação e aplicação do tratado na ordem jurídica brasileira. São Paulo: Juarez de Oliveira, 2002.

MAZZUOLI, Valério de Oliveira. A garantia do duplo grau de jurisdição em matéria criminal na Convenção Americana sobre Direitos Humanos e na jurisprudência recente do STF: uma análise a partir dos casos "Barreto Leiva vs. Venezuela" (CIDH) e "Mensalão" (STF). In: CLÈVE, Clèmerson Merlin; FREIRE, Alexandre (Coordenadores). Direitos fundamentais e jurisdição constitucional. Revista dos Tribunais: São Paulo, 2014.

MC 382/10 Comunidades Indígenas da Bacia do Rio Xingu, Pará, Brasil. Medidas cautelares outorgadas pela CIDH no ano de 2011. Disponível em:

https://www.cidh.oas.org/medidas/2011.port.htm. Acesso em: 21 de agosto de 2015. 
MINISTÉRIO DAS RELAÇÕES EXTERIORES. Candidatura brasileira à Comissão Interamericana de Direitos Humanos. 10 de maio de 2013. Disponível em: http://www.itamaraty.gov.br/index.php?option=com_content\&view=article\&id=2160\&catid= 42\&lang=pt-BR\&Itemid=280. Acesso em: 22 de agosto de 2015.

MINISTÉRIO DAS RELAÇÕES EXTERIORES. Nota 196. Eleição de Paulo Vannuchi à Comissão Interamericana de Direitos Humanos. 6 de junho de 2013. Disponível em: http://www.itamaraty.gov.br/index.php?option=com_content\&view=article\&id=3458:eleicaode-paulo-vannuchi-a-comissao-interamericana-de-direitos-humanos\&catid=42\&lang=ptBR\&Itemid=280. Acesso em: 22 de agosto de 2015.

MINISTÉRIO DAS RELAÇÕES EXTERIORES. Nota 142. Solicitação da Comissão Interamericana de Direitos Humanos (CIDH) da OEA. 05 de abril de 2011. Disponível em: http://www.itamaraty.gov.br/index.php?option=com_content\&view=article\&id=2555: solicita cao-da-comissao-interamericana-de-direitos-humanos-cidh-da-oea\&catid=42\&lang=ptBR\&Itemid=280. Acesso em: 21 de agosto de 2015.

PIOVESAN, Flávia. Brasil e os sistemas regionais de proteção dos direitos humanos. Centre for Brazilian Studies, University of Oxford, Working Paper 77, 2006, pp. 11-12. Disponível em: http://www.lac.ox.ac.uk/sites/sias/files/documents/Piovesan77WP2006.pdf. Acesso em: 19 de agosto de 2015.

PIOVESAN, Flávia. Direitos humanos e o direito constitucional internacional. 10. ed., rev. e atual. São Paulo: Saraiva, 2009.

TEIXEIRA, Gustavo de Faria Moreira. O greening no sistema interamericano de direitos humanos. Curitiba: Juruá, 2011.

TRINDADE, Antônio Augusto Cançado. A proteção internacional dos direitos humanos e o Brasil (1948-1997): as primeiras cinco décadas. 2 ed. Brasília: Editora Universidade de Brasília, 2000.

VENTURA, Deisy; CETRA, Raísa Ortiz. O Brasil e o Sistema Interamericano de Direitos Humanos: de Maria da Penha à Belo Monte. In: SILVA FILHO, José Carlos Moreira da; TORELLY, Marcelo (orgs.). Justiça de transição nas Américas: olhares interdisciplinares, fundamentos e padrões de efetivação. Belo Horizonte: Forum, 2013. Disponível em: http://webcache.googleusercontent.com/search?q=cache:C63Pk1LUrBEJ:conectas.org/arquiv ossite/Ventura\%2520Cetra\%2520O\%2520Brasil\%2520e\%2520o\%2520SIDH\%25202012\%2

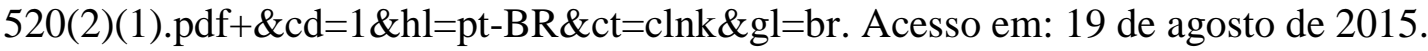

